betrayal - women's colleges, far from being the benefactors to their kind, threw up the greatest obstacles. Rossiter presents convincing evidence that:

Most of the women's traditional employers, such as women's colleges, teacher colleges, and colleges of home economics, were closing their doors... and they [women] were not included on the faculties of the growing and new co-educational institutions. Much of this new exclusion was tied to marriage, as in the reinstatement of the ante-nepotism rules on most campuses after World War II. But even single women were ousted or just not hired in the pronatalist years, often for fear that they might later get married.... Thus the pattern was deliberate and grew widespread.

Matters were to change of course, but it took at least 20 years before even a wedge was insinuated into the closed door although 'drawbridge' and 'portcullis' might be better metaphors. For not only did men return from the war and re-establish themselves in the hierarchy of the professions, with the naturally accepted attitudes of dominance, but recruitment in universities and liberal arts colleges, previously female-dominated areas, now became masculinized. Perhaps most chilling is the way in which this change was more than tacitly endorsed by foundation officials and academic administrators. So in a time that gave a young male scientist every opportunity and enhanced status, young women were "supposed to be at home with the children, whether they had them or not, or whether they wanted to be there or not".

Discrimination was a word that did not come into use until the late 1960 s. Before then the social patterns were seen as just the way things were, always had been and should always remain. So those professional women who clearly understood what was happening, who did see a pattern and reported it, were understandably reluctant to criticize the powerful and successful. Even those who actually tried to do something, to correct the situation, were more often than not ineffectual. Some were ineffectual because of the strength of the opposition: Margaret Mitchell's article in 1951 on these matters was shot out of the sky by a counterblast from a Harvard psychologist of such force and venom that the topic was never raised again for a decade. Sometimes they were ineffectual through their own muddled thinking and passion for compromise, as when a committee of Harvard Faculty and Radcliffe Trustees wrote a report on the limits of women's opportunities in the academic world that was so bland and compromising it was totally counterproductive. Yet such was the prevailing mindset, and social ambience, that, as Rossiter claims, if the data had been interpreted to demonstrate discrimination, they would probably not have been published; if they had been published, more likely than not they would have been ignored.

When the change came, it came not from within science but from the activities of many social scientists set against a larger social reality. And there was now one new element within this larger reality that had nothing to do with the science.

The civil rights movement proved to be the agent. Rossiter argues that Alice Rossi, who devoted many years in the early 1960 s to rethinking and reformulating prevailing wisdom, was able to come up with a new view only because, in the context of the civil rights movement, she could really see a pattern. True, others had too, but she could delineate the complex of oppressive attitudes and practices. Women in science did not deserve their fate and should not be blamed for their obscurity, in the same way that blacks did not deserve their fate and could not be blamed for it, either. Society could and should be changed; laws would have to be passed by Congress, however reluctant, and finally the executive branch would have to be pressured into enforcing the laws. By 1969, the anger of women had coalesced into a movement; innumerable reports on the status of women followed, angering even more women as the totality of their exclusion was documented further and brought fully into view. By 1970, federal hearings on sex discrimination on the campus and workforce were being held; by 1972 , landmark legislation was in place on equal pay and affirmative action in academic institutions.

This then is the general thesis for which the 16 chapters in this book provide irrefutable evidence, assembled with the careful scholarship that has become Rossiter's hallmark. Once again, the quantity of material researched is enormous, and my caveats are few. So much is involved in these 20 years, so much to be covered, that I found the book heavier going than its predecessor, with fewer of the light touches of irony and humour that I had enjoyed so much before. Rossiter declares in her final sentence that these 32 years marked "the ending of an era and the beginning of a new and more equitable one". Yet those who rejoice and applaud what has happened should always reflect that, as George Steiner once wrote about science, there will always be moral ambushes waiting for us. Nothing will be clear-cut and simple. Reading social history, whether George Trevelyan's, Asa Briggs' or Margaret Rossiter's, I am pulled back time and again to what William Blake wrote in The Vision of John Bull: "I ponder on how men fight and lose the battle and the thing they fought for comes about in spite of their defeat. And when it comes turns out to be not what they meant and other people have to fight for what they meant under another name."

June Goodfield, emeritus professor at George Mason University, Fairfax, Virginia, is at International Health and Biomedicine, The Manor House, Alfriston, East Sussex BN26 5SY, UK.

\title{
Sceptical wonderment
}

\section{Alan Cromer}

The Demon-Haunted World: Science as a Candle in the Dark. By Carl Sagan. Random/Headline: $1996 . \quad$ Pp. 436. $\$ 25.95$, £18.99.

CARL Sagan's high "wonder quotient” was tempered at an early age by the scepticism of Martin Gardner's Fads and Fallacies in the Name of Science. And wonder and scepticism have been "uneasily cohabiting" modes of thought throughout Sagan's career. Both he and Gardner have long been affiliated with the Committee for the Scientific Investigation of Claims of the Paranormal, publisher of the Skeptical Inquirer $(S I)$, and Sagan writes as a committed, indeed, a crusading, sceptic about many of the incredible beliefs familiar to $S I$ readers. There is much fun to be had in reading about the debunking of such 'mysteries' as the English crop circles (produced by a pair of dedicated pranksters) and the crash in Roswell, New Mexico, of an alien spacecraft (a secret high-altitude military balloon).

Sagan writes regularly for Parade, a Sunday newspaper magazine that reaches a staggering 37 million US households (83 million readers). Seven chapters in this book are an expansion of a 1993 Parade article on why he does not believe in alien abductions. Other chapters were written on different occasions for different audiences, making for much repetition and confusion of purpose. Some are clearly for students in his Cornell University course on critical thinking, some are based on articles in Parade, some are for scientists, and the final chapter is based on an address given at an induction ceremony for new US citizens.

Sagan is a forceful advocate for science and a fierce opponent of pseudoscience, mysticism and religion. "Science", he writes, "is different from any another human enterprise... in its passion for framing testable hypotheses, in its search for definite experiments that confirm or deny ideas, and in the vigour of its sub- 
stantive debate, and in its willingness to abandon ideas that have been found wanting." But as good as this sounds, it fails to acknowledge the central importance to science of a theoretical framework. Of all the many claims of the paranormal that Sagan catalogues, only perpetual motion is rejected on theoretical grounds; all the others are rejected for lack of evidence. Thus, both in theory and practice, Sagan takes an essentially empirical-inductivist view of science.

This leaves him combating pseudoscience with one arm tied behind his back, for without a positive theoretical reason ("We know things don't work that way!") the mere lack of evidence is a weak argument against belief. No matter how many alien abduction scenarios and UFO sightings are explained away, one can never answer the reasonable question of one of his Parade readers: "A hallucination might account for $99 \%$ [of reported alien abductions], but can it ever account for $100 \%$ ?"

Since at least the time of Archimedes, science has deduced results from very general principles, which are not themselves capable of direct verification. The Greeks, for example, deduced the law of reflection from the principle that light should travel the shortest distance from the eye to the object. From the law of reflection, they deduced the images formed by plane and curved mirrors.

This is difficult stuff, and requires much training and study to learn. Sagan says the same about modern science at several points in the book, but in one chapter he vehemently contests the view that science is not part and parcel of human nature. Science is a natural proclivity, he asserts, that "is embedded deeply within us". Science is not hard to teach because it is hard, but because "indifference, inattention, incompetence, or fear of scepticism... discourage children from science". Why there is so much incompetency and fear of a natural proclivity is not explained, although elsewhere he admits that seven-year-olds are much better at wonder than scepticism.

The innateness of science is a deeply held Sagan belief. He denies that science had a unique origin in ancient Greece, claiming that the tracking know-how of preliterate peoples is science comparable to that of the Greeks. This claim goes beyond rejecting the theoretical accomplishments of the Greeks, to rejecting his own views of science given elsewhere in the book. If tracking know-how is science, why not make the same claim for a chimpanzee's ability to collect termites with a grass reed? Amazingly, Sagan does, defending his belief as uncritically as any alien abductee.

Sagan's passionate advocacy for science and scepticism uneasily cohabits with his passionate advocacy of shaky scientific, political, social and moral posi- tions. The result is a book with an abundance of material on which an aspiring sceptic can practise.

Alan Cromer is in the Department of Physics, Northeastern University, Boston, Massachusetts 02115, USA.

\section{Regal recipes}

\section{John Mann}

Classics in Total Synthesis: Targets, Strategies, Methods. By K. C. Nicolaou and E. J. Sorenson. VCH: 1996. Pp. 798. DM128, \$80, £52 (hbk); DM78, \$49.95, $£ 32$ (pbk).

IT is not often that a chemical structure graces the front cover of Nature, but such was the honour accorded to the complex natural product taxol* on 17 February 1994. It advertised the publication (in that issue - Nature 367, 630; 1994) of a paper recording an elegant total synthesis of taxol by K. C. Nicolaou and colleagues. The molecule had provided a formidable challenge (and still does) with its 11 stereocentres and dense array of functionality, yet the synthetic pathway reported was intriguingly simple, stereoselective and at least partially convergent. In short, a classic total synthesis and one of the 36 such syntheses gathered together by Nicolaou and Sorenson in this book.

But what constitutes a classic total synthesis? The authors have restricted themselves to natural products rather than theoretically interesting molecules such as cubane or dodecahedrane, or man-made structures such as dendrimers or spherands. So most of the examples demonstrate the great artistry and ingenuity of synthetic chemists as they struggled to assemble ever more complex natural products during the past 40 years. Much of this artistry depended on the invention of new reactions or methods for the control of stereochemistry, and perhaps most importantly on the ability to analyse the problem before starting the syntheses. E. J. Corey's exposition of the rules of retrosynthetic analysis in the late 1960s revolutionized the way chemists plan a synthesis, and his book The Logic of Chemical Synthesis (Wiley, 1989) summarized the methodology and reviewed his own 'classic' syntheses.

Each of the 36 chapters in Nicolaou and Sorenson's book spotlights one natural product and reveals the intimate details of its synthesis. Woodward's route to strychnine is not unexpectedly in 'poll position', not least because of its ingenuity and use of none but the simplest of chemical reagents. Although completed in 1954,

* Bristol-Myers Squibb has registered Taxol as a trade mark and wishes the scientific community to use the name paclitaxel. it remained the only total synthesis of this complex molecule until the newer routes of Magnus, Overman and others appeared in the early 1990 s. It was also important for demonstrating that a complex molecule could succumb to total synthesis, and so encouraged others to take the plunge. Woodward was also involved, with Eschenmoser, in the 12-year international effort that culminated in the synthesis of vitamin B12 in 1973. Like so many of the syntheses detailed in the book, the invention of new enabling chemistry along the way was just as important as the final triumph, and these novel reactions are highlighted throughout the text.

Not all of the molecular targets are complex, and the synthesis of the simple monoterpene menthol by Takasago and colleagues is used to exemplify important advances in catalytic asymmetric reactions. The preparation of the simple hexoses using Masamune-Sharpless asymmetric epoxidation and related techniques provides a further insight into the power of these new techniques. But it is the big molecules (the 'synthetic Everests') that take pride of place. Synthesis of the antineoplastic macrolide cytovaricin provides an opportunity to explore the use of the Evans chiral auxiliaries in asymmetric synthesis; and the preparation of the immunosuppressant rapamycin involves an examination of the palladium-catalysed reactions introduced by Heck, Stille and Suzuki. The current vogue for tandem radical processes is brought to the fore in the chapter on hirsutene synthesis, and 18 other syntheses that use this strategy are also discussed. The last two chapters reveal the enormous complexity of marine natural products and chronicle the triumphs of Kishi's and Nicolaou's groups in their syntheses of palytoxin and brevetoxin B.

Along with all this methodology, each chapter includes essential information about the occurrence and biological significance of the natural products, a full retrosynthetic analysis of the target structure and a detailed account of the actual synthesis. Mechanisms of the reactions and problems encountered are also examined. The quality of the illustrations is superb and there is a comprehensive list of references in each chapter. The book is not only a record of synthetic achievement during the past 40 years, but also a valuable research and teaching aid.

Not everyone will agree with the authors' choice of 'classics'. The few European contributions, for instance, are largely buried within the various chapters. But there is no denying that this superb book about the art and science of natural product synthesis will be an essential purchase for many organic chemists.

John Mann is in the Department of Chemistry, University of Reading, Reading RG6 6AD, UK.

NATURE - VOL $380 \cdot 28$ MARCH 1996 